\title{
Aberrant UBR4 expressions in Hirschsprung disease patients
}

\author{
Gunadi $^{{ }^{*}}$ D , Alvin Santoso Kalim², Estelita Liana², Aditya Rifai Fauzi ${ }^{2}$, Dian Nirmala Sirait ${ }^{3}$, Dwiki Afandy ${ }^{2}$, \\ Sagita Mega Sekar Kencana ${ }^{2}$, Eko Purnomo ${ }^{4}$, Kristy Iskandar ${ }^{5}$ and Akhmad Makhmudi ${ }^{2}$
}

\begin{abstract}
Background: Recently, pathogenic alleles within ubiquitin N-recognin domain-containing E3 ligase 4 (UBR4) gene have been shown to be associated with Hirschsprung disease (HSCR). We determined the UBR4 expressions in Indonesian HSCR patients.

Methods: We analyzed the UBR4 expressions in the colons of HSCR patient and anorectal malformation (ARM) patient as control by real-time polymerase chain reaction (qPCR).

Results: Thirty-seven patients with non-syndromic HSCR and eighteen controls were involved in this study. GPCR revealed that the UBR4 expression was strongly decreased $(0.77$-fold) in the ganglionic group of patients with HSCR compared to the control group with ARM $\left(\Delta C_{\mathrm{T}} 2.43 \pm 0.36\right.$ vs. $\left.2.05 \pm 0.69 ; p=0.009\right)$, whereas the UBR4 expression was also significantly reduced (0.79-fold) in the aganglionic group of patients with HSCR compared to the control group with ARM $\left(\Delta C_{\mathrm{T}} 2.39 \pm 0.46\right.$ vs. $\left.2.05 \pm 0.69 ; p=0.044\right)$. However, the UBR4 expression change was not associated with gender $(p=0.35$ and 0.80$)$, nor with degree of aganglionosis both in ganglionic and aganglionic colons $(p=0.72$ and 0.73 ), respectively.
\end{abstract}

Conclusion: Our study demonstrates that expression of UBR4 is decreased in both aganglionic and ganglionic colon of HSCR patients.

Keywords: Aberrant expression, $\mathrm{Ca}^{2+}$ signaling, Hirschsprung disease, Indonesia, Pathogenesis, UBR4

\section{Background}

Hirschsprung disease (HSCR) is a multifactorial disease characterized by the absence of ganglion cells in the bowel, causing a functional ileus in infants. It is divided into short-aganglionosis, long-aganglionosis, and total colon aganglionosis [1, 2]. Its frequency in Indonesia is higher $(3.1: 10,000)[3]$ than other populations $[1,2]$. This difference might be associated with the higher risk allele frequency of $R E T$ rs 2435357 and rs 2506030 in Indonesia compared with other populations $[4,5]$.

Ubiquitin N-recognin domain-containing E3 ligase 4 (UBR4) is a ubiquitin ligase protein that interacts with $\mathrm{Ca}^{2+}$ bound calmodulin in cytoplasm and might act as a regulator of $\mathrm{Ca}^{2+}$, that is released through ITPR1 [6]. Bowel motility is determined by the synchronized

*Correspondence: drgunadi@ugm.ac.id

${ }^{1}$ Pediatric Surgery Division, Department of Surgery/Genetics Working Group, Faculty of Medicine, Public Health and Nursing, Universitas Gadjah Mada/Dr. Sardjito Hospital, Yogyakarta 55281, Indonesia

Full list of author information is available at the end of the article activity of enteric nervous system (ENS), extrinsic nerves, immune cells, interstitial cells of Cajal (ICCs), and smooth muscle cells (SMCs) [7]. ICCs are essential to generate and propagate the electrical cyclical activity (slow waves) in the intestines. The slow waves are transferred into the SMCs to make it depolarize cyclically, resulting in activation of calcium entry and intestines' contraction [7]. In addition, previous study showed that UBR4 is one of the novel HSCR genes with an excess of pathogenic alleles in HSCR patients and is expressed in the developing human and mouse fetal gut [8]. Also, there is significant loss of enteric neuronal precursors after ubr4-knockdown in zebrafish embryos [8]. Therefore, we determined the UBR4 expressions in Indonesian HSCR patients with the hypothesis of the UBR4 expressions decrease in the colon of patients with HSCR.

(c) The Author(s). 2019 Open Access This article is distributed under the terms of the Creative Commons Attribution 4.0 International License (http://creativecommons.org/licenses/by/4.0/), which permits unrestricted use, distribution, and reproduction in any medium, provided you give appropriate credit to the original author(s) and the source, provide a link to the Creative Commons license, and indicate if changes were made. The Creative Commons Public Domain Dedication waiver (http://creativecommons.org/publicdomain/zero/1.0/) applies to the data made available in this article, unless otherwise stated. 
Table 1 Baseline characteristics of HSCR patients in Dr. Sardjito Hospital, Indonesia

\begin{tabular}{ll}
\hline Characteristics & $N(\%) ;$ median (IQR) \\
\hline Gender & $26(70.3)$ \\
- Male & $11(29.7)$ \\
- Female & \\
Type of aganglionosis & $29(78.4)$ \\
- Short-segment & $8(21.6)$ \\
- Long-segment & 0 \\
- Total colon aganglionosis & $4(1-34)$ \\
Age at HSCR diagnosis (months) & $6(2-30)$ \\
Age at definitive surgery (months) & \\
Definitive surgery & $17(46)$ \\
- Transanal endorectal pull-through & $13(35)$ \\
- Transabdominal Soave & $7(19)$ \\
- Duhamel &
\end{tabular}

HSCR Hirschsprung disease, IQR interquartile range

\section{Material and methods}

\section{Patients}

We involved HSCR patients who underwent pull-through from December 2014 until May 2019 at Dr. Sardjito Hospital, Indonesia [9]. Their parents gave a signed informed consent before joining the study.

We obtained the ganglionic and aganglionic colon of HSCR patients during a pull-through and control colons during a stoma closure from anorectal malformation patients [9].

The Institutional Review Board (IRB) of the Faculty of Medicine, Public Health and Nursing, Universitas Gadjah Mada/Dr. Sardjito Hospital, approved the study (KE/FK/1105/EC/2018).

\section{Real-time polymerase chain reaction (qPCR)}

Total RNA was obtained from HSCR patients and control colons according to our previous study [9], followed by a qPCR to determine the UBR4 expression using the following primer sets: 5' - TGGACACTCAGCTC ACCAAG-3' (forward) and 5'-GTTCCATCTTGACG CTCCTC-3' (reverse) [10]. Glyceraldehyde-3-phosphate dehydrogenase (GAPDH) was employed as a reference gene for analysis of $U B R 4$ expression. We used the Livak method to compare the UBR4 expressions between HSCR patients and control colons $[9,11]$.

\section{Statistics}

Data was provided as mean \pm standard deviation (SD), median (interquartile range, IQR), or frequency. We utilized t-test to determine the significant differences of UBR4 expression between the ganglionic, aganglionic, and control colon group. We determined a significant level by $p$-value of $<0.05$.

\section{Results}

\section{Baseline characteristics}

We involved 37 non-syndromic sporadic HSCR patients and 18 controls. Our patients revealed short-aganglionosis (70\%) and long-aganglionosis (30\%). Almost half of patients (46\%) had transanal endorectal pull-through (46\%). The median age at HSCR diagnosis was 4 (IQR, 1-34) months (Table 1).

\section{UBR4 expressions in HSCR patients}

qPCR revealed that the expression of $U B R 4$ was strongly decreased (0.77-fold) in the ganglionic compared to the control group $\left(\Delta \mathbf{C}_{\mathbf{T}} 2.43 \pm 0.36\right.$ vs. $2.05 \pm 0.69 ; p=$ 0.009 ), whereas the UBR4 expression was also significantly reduced (0.79-fold) in the aganglionic compared to the control group $\left(\Delta \mathbf{C}_{\mathbf{T}} 2.39 \pm 0.46\right.$ vs. $2.05 \pm 0.69$; $p=0.044)$ (Table 2 and Fig. 1).

Next, we compared the UBR4 expressions between ganglionic and aganglionic colon group. qPCR showed that the UBR4 expressions were not significantly different between two groups $\left(\Delta \mathbf{C}_{\mathbf{T}} 2.43 \pm 0.36\right.$ vs. $2.39 \pm 0.46$; $p=0.64)$.

\section{Association between UBR4 expressions and baseline characteristic of HSCR patients}

We examined the association between UBR4 expressions with gender and degree of aganglionosis in HSCR patients in this cohort. The UBR4 expressions were not significantly associated with gender $(p=0.35$ and 0.80$)$, nor with type of aganglionosis both in ganglionic and aganglionic colons $(p=0.72$ and 0.73$)$, respectively (Table 3).

\section{Discussion}

We are able to show for the first time the aberrant UBR4 expression in HSCR patients. We determined UBR4 expressions in the aganglionic, ganglionic, and control colons using qPCR. Our study reveals a

Table 2 The UBR4 expressions in the HSCR patients and control colons

\begin{tabular}{lllll}
\hline & $U B R 4\left(\Delta C_{T} \pm S D\right)$ & $\Delta \Delta C_{T}(95 \% \mathrm{Cl})$ & Fold change $\left(2^{-\Delta \Delta C}\right)$ & $p$-value \\
\hline Ganglionic colon & $2.43 \pm 0.36$ & $0.39(0.10-0.67)$ & 0.77 & $0.009^{*}$ \\
Aganglionic colon & $2.39 \pm 0.46$ & $0.34(0.01-0.67)$ & 0.79 & $0.044^{*}$ \\
Control colon & $2.05 \pm 0.69$ & & & \\
\hline
\end{tabular}

${ }^{*}, p<0.05$ is considered statistically significant; HSCR, Hirschsprung disease 




Fig. 1 The UBR4 expression was significantly down-regulated $(0.77$-fold) in the ganglionic colon group compared to the control group ( $p=0.009)$, whereas the UBR4 expression was also significantly decreased (0.79-fold) in the aganglionic colon group compared to the control group $(p=0.044) .{ }^{*}, p<0.05$ is considered statistically significant

significant difference of $U B R 4$ expression between HSCR patients' colons and control colons, implying that the aberrant UBR4 expression could be one of the contributing factors of Indonesian HSCR patients.

UBR4 has a role in $\mathrm{Ca}^{2+}$ signaling and is involved in neuronal excitability [12] since it interacts with $\mathrm{Ca}^{2+}$ bound calmodulin in cytoplasm and acts as a regulator of $\mathrm{Ca} 2+$, which is released through ITPR1 [6]. $\mathrm{Ca}^{2+}$ signaling is important to maintain the intestines' motility, together with the synchronized activity of ENS, extrinsic nerves, immune cells, ICCs, and SMCs [7]. The intestines' contraction is induced by the activation of calcium entry due to cyclically depolarization of SMCs. ICCs generate and propagate the slow waves to be transferred into SMCs [7]. HSCR pathogenesis includes the compromised condition of genes responsible for the ENS development $[1,2,4,5,8]$, the neurotransmitters expressed by the ENS neurons [13] and/or their interactions. Recently, pathogenic alleles within the UBR4 gene have been shown to be associated with HSCR [8]. Furthermore, a recent study demonstrated that the death of Ubr4-deficient mice embryos was correlated with developmental defects in various processes, including neurogenesis, due to failure to preserve cell integrity and adhesion [14]. It has been shown that neurogenesis in embryos is strongly affected by the dysregulation of cell adhesion molecules [15]. Lack of UBR4 causes the rapid depletion of other cells' surface proteins as well, such as platelet-derived growth factor receptor (PDGFR) [14]. In addition, previous study revealed that SK3 is highly expressed in the PDGFR $\alpha+$ cells [13], which together with ICCs and SMCs regulate intestinal peristalsis [16]. Our results further support the importance of UBR4 in the HSCR pathogenesis by providing new evidence of the aberrant UBR4 expressions in HSCR patients' colons. We hypothesize that the aberrant UBR4 expressions contribute to the pathogenesis of HSCR in our patients by affecting the expression of SK3 in the PDGFR $\alpha+$ cells.

Moreover, our study for the first time demonstrated that the decreased UBR4 expression also occurred in the ganglionic colon of HSCR patients. It has been shown that several aberrant gene expressions, including SK3 [9, 17], Cx26 and Cx43 [18], and NOS [19], were significantly associated with the persistent intestinal symptoms in HSCR patients after an appropriately completed surgery. Whether the aberrant UBR4

Table 3 Association between UBR4 expressions and baseline characteristics of HSCR patients

\begin{tabular}{llllll}
\hline UBR4 & Male $(n=26)\left(\Delta \mathrm{C}_{\mathrm{T}} \pm \mathrm{SD}\right)$ & Female $(n=11)\left(\Delta \mathrm{C}_{\mathrm{T}} \pm \mathrm{SD}\right)$ & $\Delta \Delta \mathrm{C}_{\mathrm{T}}(95 \% \mathrm{Cl})$ & Fold change $\left(2^{\left.-\Delta \Delta \mathrm{C}_{\mathrm{T}}\right)}\right.$ & $p$-value \\
Ganglionic Colon & $2.40 \pm 0.37$ & $2.52 \pm 0.35$ & $-0.12(-0.38-0.14)$ & 1.09 & \\
Aganglionic Colon & $2.38 \pm 0.48$ & $2.42 \pm 0.45$ & $-0.05(-0.41-0.32)$ & 1.03 & 0.35 \\
& Short-segment $(n=29)\left(\Delta \mathrm{C}_{\mathrm{T}} \pm \mathrm{SD}\right)$ & Long-segment $(n=8)\left(\Delta \mathrm{C}_{\mathrm{T}} \pm \mathrm{SD}\right)$ & & & \\
Ganglionic Colon & $2.42 \pm 0.38$ & $2.48 \pm 0.30$ & $-0.05(-0.35-0.24)$ & 1.04 & \\
Aganglionic Colon & $2.40 \pm 0.46$ & $2.32 \pm 0.55$ & $0.08(-0.39-0.55)$ & 0.95 & 0.72 \\
\hline
\end{tabular}


expression in the ganglionic colon is also correlated with the persistence of bowel symptoms after pullthrough in HSCR patients warrants further investigation.

It should be noted that our study used ARM patient colon as control. To the best of our knowledge, there is no study comparing the UBR4 expression between ARM patient colon and other colonic specimens. These facts should be considered during the interpretation of our findings since most ARM patients also show the intestinal motility problem [20]. Therefore, further analysis using controls without any bowel motility problem is needed to confirm our results.

Moreover, future studies are necessary to further confirm the role of UBR4 in the pathogenesis of HSCR by checking the decreased of UBR4 protein expressions using western blot or immunohistochemistry and screening the pathogenic variant in the UBR4 gene using sequencing in HSCR patients.

\section{Conclusion}

Our study demonstrates that expression of UBR4 is decreased in both aganglionic and ganglionic colon of HSCR patients.

\author{
Abbreviations \\ ENS: Enteric nervous system; GAPDH: Glyceraldehyde-3-phosphate \\ dehydrogenase; HSCR: Hirschsprung disease; ICCs: Interstitial cells of \\ Cajal; qPCR: Quantitative real-time polymerase chain reaction; \\ SMCs: Smooth muscle cells; UBR4: Ubiquitin N-recognin domain- \\ containing E3 ligase 4
}

\section{Acknowledgements}

We are thankful to Sumantra Chatterjee (NYU School of Medicine, USA) for his suggestions on the paper and an English native speaker at Faculty of Medicine, Public Health and Nursing, UGM, for checking our manuscript.


critically revised the manuscript for important intellectual content. ASK, EL, ARF, DNS, DA, and SMSK performed the total RNA extraction, $\mathrm{QPCR}$, and collected the baseline data. G and ASK analyzed the data. All authors have approved the manuscript, and agreed to be accountable for all aspects of the study.

\section{Funding}

A grant was given by the Indonesia Ministry of Research, Technology and Higher Education (World Class Research No. 1979/UN1.DITLIT/DIT-LIT/LT/2019 to $G$.).

\section{Availability of data and materials}

All data generated during this study are contained in the submission. The raw data are available from the corresponding author on reasonable request.

\section{Ethics approval and consent to participate}

The Institutional Review Board of Faculty of Medicine, Public Health and Nursing, Universitas Gadjah Mada/Dr. Sardjito Hospital approved this study (KE/FK/1105/EC/2018). The parents of HSCR patients and controls gave a signed informed consent before joining the study.

\section{Consent for publication}

Not applicable.

\section{Competing interests}

The authors declare that they have no competing interests.

\section{Author details}

${ }^{1}$ Pediatric Surgery Division, Department of Surgery/Genetics Working Group, Faculty of Medicine, Public Health and Nursing, Universitas Gadjah Mada/Dr. Sardjito Hospital, Yogyakarta 55281, Indonesia. ${ }^{2}$ Genetics Working Group, Faculty of Medicine, Public Health and Nursing, Universitas Gadjah Mada, Yogyakarta 55281, Indonesia. ${ }^{3}$ Pediatric Surgery Division, Department of Surgery, Faculty of Medicine, Public Health and Nursing, Universitas Gadjah Mada/Dr. Sardjito Hospital, Yogyakarta 55281, Indonesia. ${ }^{4}$ Pediatric Surgery Division, Department of Surgery/Genetics Working Group, Faculty of Medicine, Public Health and Nursing, Universitas Gadjah Mada/UGM Academic Hospital, Yogyakarta 55291, Indonesia. ${ }^{5}$ Department of Child Health/Genetics Working Group, Faculty of Medicine, Public Health and Nursing, Universitas Gadjah Mada/UGM Academic Hospital, Yogyakarta 55291, Indonesia.

Received: 10 June 2019 Accepted: 8 December 2019

Published online: 12 December 2019

\section{References}

1. Chakravarti A, Lyonnet S. Hirschsprung disease. In: Scriver CR, Beaudet AL, Valle D, Sly WS, Childs B, Kinzler K, Vogelstein B, editors. The metabolic and molecular bases of inherited disease. 8th ed. New York: McGraw-Hill; 2001.

2. Amiel J, Sproat-Emison E, Garcia-Barcelo M, et al. Hirschsprung disease, associated syndromes and genetics: a review. J Med Genet. 2008:45:1-14

3. Gunadi, Karina SM, Dwihantoro A. Outcomes in patients with Hirschsprung disease following definitive surgery. BMC Res Notes. 2018;11:644.

4. Gunadi, Iskandar K, Makhmudi A, Kapoor A. Combined genetic effects of RET and NRG1 susceptibility variants on multifactorial Hirschsprung disease in Indonesia. J Surg Res. 2019;233:96-9.

5. Gunadi, Kapoor A, Ling AY, et al. Effects of RET and NRG1 polymorphisms in Indonesian patients with Hirschsprung disease. J Pediatr Surg. 2014;49: 1614-8.

6. Parsons K, Nakatani Y, Nguyen MD. p600/UBR4 in the central nervous system. Cell Mol Life Sci. 2015;72:1149-60.

7. Beyder A, Farrugia G. Targeting ion channels for the treatment of gastrointestinal motility disorders. Ther Adv Gastroenterol. 2012;5:5-21.

8. Tilghman JM, Ling AY, Turner TN, et al. Molecular genetic anatomy and risk profile of Hirschsprung's disease. N Engl J Med. 2019;380:1421-32.

9. Gunadi, Sunardi M, NYP B, Kalim AS, Iskandar K, Dwihantoro A. The impact of down-regulated SK3 expressions on Hirschsprung disease. BMC Med Genet. 2018;19:24.

10. Rinschen MM, Bharill $\mathrm{P}, \mathrm{Wu} X$, et al. The ubiquitin ligase Ubr4 controls stability of podocin/MEC-2 supercomplexes. Hum Mol Genet. 2016;25: $1328-44$.

11. Livak KJ, Schmittgen TD. Analysis of relative gene expression data using real-time quantitative PCR and the 2(-Delta Delta C(T)) method. Methods. 2001;25:402-8.

12. Conroy J, McGettigan P, Murphy R, et al. A novel locus for episodic ataxia: UBR4 the likely candidate. Eur J Hum Genet. 2014;22:505-10.

13. Kurahashi M, Nakano Y, Hennig GW, et al. Platelet-derived growth factor receptor alpha-positive cells in the tunica muscularis of human colon. J Cell Mol Med. 2012;16:1397-404.

14. Kim ST, Lee YJ, Tasaki T, et al. The N-recognin UBR4 of the N-end rule pathway is required for neurogenesis and homeostasis of cell surface proteins. PLoS One. 2018;13:e0202260.

15. Enriquez-Barreto L, Palazzetti C, Brennaman LH, Maness PF, Fairén A. Neural cell adhesion molecule, NCAM, regulates thalamocortical axon pathfinding and the organization of the cortical somatosensory representation in mouse. Front Mol Neurosci. 2012;5:76

16. Kurahashi $\mathrm{M}$, Zheng $\mathrm{H}$, Dwyer $\mathrm{L}$, et al. A functional role for the 'fibroblast-like cells' in gastrointestinal smooth muscles. J Physiol. 2011; 589(Pt 3):697-710.

17. Coyle D, O'Donnell AM, Puri P. Altered distribution of small-conductance calcium-activated potassium channel SK3 in Hirschsprung's disease. J Pediatr Surg. 2015;50:1659-64. 
18. Coyle D, Doyle B, Murphy JM, O'Donnell AM, Gillick J, Puri P. Expression of connexin 26 and connexin 43 is reduced in Hirschsprung's disease. J Surg Res. 2016;206:242-51.

19. Cheng LS, Schwartz DM, Hotta R, Graham HK, Goldstein AM. Bowel dysfunction following pullthrough surgery is associated with an overabundance of nitrergic neurons in Hirschsprung disease. J Pediatr Surg. 2016;51:1834-8.

20. Levitt MA, Peña A. Anorectal malformations. Orphanet J Rare Dis. 2007;2:33.

\section{Publisher's Note}

Springer Nature remains neutral with regard to jurisdictional claims in published maps and institutional affiliations.

Ready to submit your research? Choose BMC and benefit from:

- fast, convenient online submission

- thorough peer review by experienced researchers in your field

- rapid publication on acceptance

- support for research data, including large and complex data types

- gold Open Access which fosters wider collaboration and increased citations

- maximum visibility for your research: over $100 \mathrm{M}$ website views per year

At BMC, research is always in progress.

Learn more biomedcentral.com/submissions 